\title{
A phage display combined with DNA affinity magnetic system can be applied to a screening of DNA binding proteins, such as transcription factors
}

\author{
Kusumadewi Sri Yulita ${ }^{\# 1}$ \\ Research Institute for Bioresources \\ Okayama University \\ Japan \\ Takafumi Kouno ${ }^{1}$ \\ Research Institute for Bioresources \\ Okayama University \\ Japan \\ Bunichi Ezaki* \\ Research Institute for Bioresources \\ Okayama University \\ Japan \\ E-mail: bezaki@rib.okayama-u.ac.jp
}

Financial support: Ministry of Education, Culture, Sports, Science and Technology of Japan [(Grant-in-Aid for Scientific Research for Postdoc fellowship No. 16-04467 to Y.K. and B.E.) and (Grant-in-Aid for Scientific Research (C)(2) No. 16580046 to B.E.)] and JSPS Joint Project under JapanKorea Cooperative Science Program to B.E.

Keywords: AtGST11 gene, biopanning, DNA binding proteins, T7 phage differential display, transcription factors.

Present address: "Indonesia Institute of Science Cibinong Science Centre JI Raya Bogor Km. 46 Cibinong 16911, Indonesia.

${ }^{1}$ These two authors contributed equally as first authors in this study.

Abbreviations: cDNA: complementary DNA

DIG: digoxigenin

MS medium: Murashige and Skoog medium

PCR: polymerase chain reaction

SA-PMP: streptavidin paramagnetic particle

SSC: $150 \mathrm{mM} \mathrm{NaCl}, 15 \mathrm{mM}$ sodium citrate buffer (pH 7.0)

Here we introduce a new approach for the screening of DNA binding proteins, using a phage library based on a phage display technique. In principal, a complementary DNA (cDNA) library based on the recombinant bacteriophage T7 expressing target proteins on its capsid (phage display) is constructed. These phage particles are hybridized with a biotinylated target DNA fragment which is immobilized on the surface of streptavidin paramagnetic particle (SA-PMP). The phage particles are released from the target DNA fragment by a nuclease treatment and the recovered phages are used to the next round of hybridization. These processes are repeated three times to amplify the target phages in the population. This simple method is faster, and more systemic than other current methods (e.g. yeast one hybrid system). As a proof of this principle, we tried to isolate transcription factors which specifically bind to the promoter region of the Arabidopsis thaliana AtGST11 gene. Two obtained candidates, RING zinc finger protein and AtHB6, showed DNA binding activity to the AtGST11 promoter region. We could validate that our new application of phage display is a superior method for isolation of DNA binding proteins with a broad range of potential applications.

Organisms are always exposed to various changes in their environments and should quickly and adequately response to these changes for their survivals. Stress specific geneexpressions should be timely accomplished via stress specific signal transductions. Differential gene expression is also a major determinant in development event in organism and each gene exhibits a specific temporal and spatial expression pattern. Various transcription factors have been reported to function for stress dependent geneexpression. These factors generally recognize and bind to unique 10-15 bp DNA sequences in or near the promoter regions and these bindings cause a change in DNA

*Corresponding author 


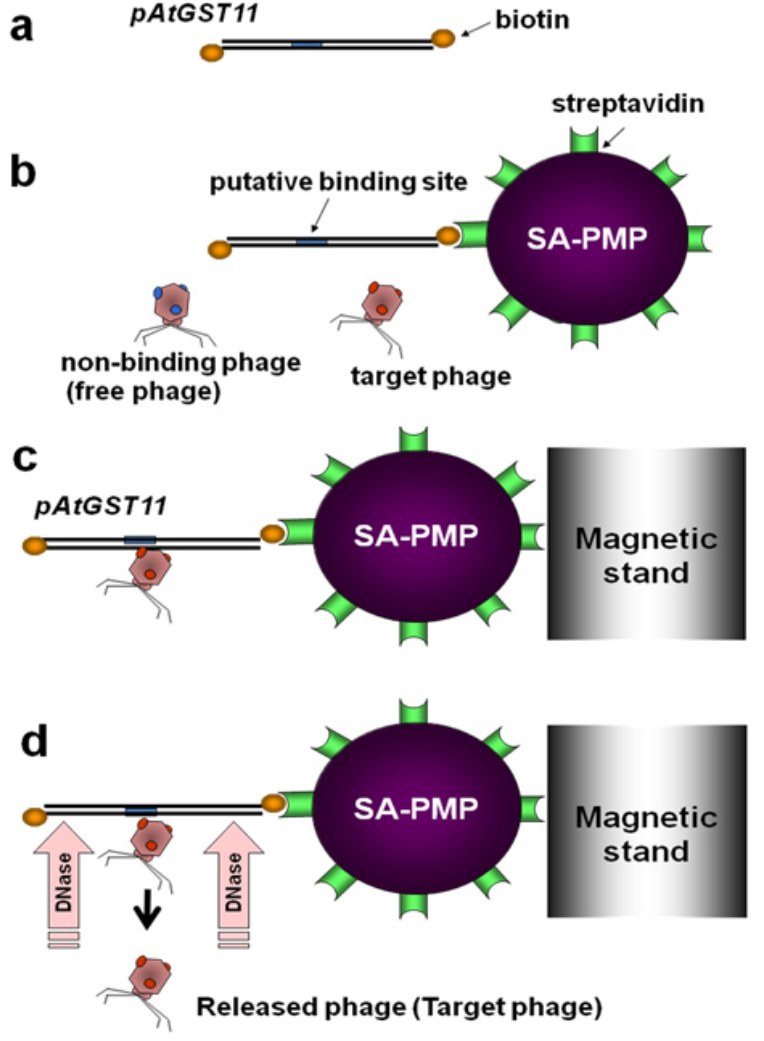

Figure 1. Schematic diagram of screening. (a) Both sides of the DNA probe (600 bp upstream region of the AtGST11 gene) were 3 'end-labeled with biotin by a terminal deoxynucleotidyl transferase. (b) The DNA probe was captured with SA-PMP in the reaction solution and recombinant phages were added to the solution to make DNA/phage complex. (c) The complex was trapped to a magnetic stand and rinse with a washing solution to remove non-binding phages. (d) DNasel treatment was performed to release the phages from the binding site. These steps ( $a$ to $d$ ) were repeated three times to increase the number of candidates in the population.

conformation to enhance the transcription by RNA polymerase complex.

Yeast one hybrid system is one of the most widely used systems in many studies to isolate and characterize transcription factors which can directly bind to target DNA sequences, but there are several disadvantages in this system. First of all, this system is only fit for a 10-15 bp short DNA sequences, but completely not for a comprehensive screening of the transcription factors using a whole part of the target promoter region. Second, the process of one hybrid system is complicated and contains many steps to isolate candidates encoding the transcription factors. Moreover, it is hard to get reproducible results in this system. Because the binding strength between the target DNA and the protein is indirectly estimated by a sensitivity of yeast cells for 3-amino-1H-1, 2, 4-triazole (3AT).
Our study described a development of a simple technique to screen DNA binding proteins expressed on the viral capsids of certain bacteriophages, using streptavidin paramagnetic particle (SA-PMP) and biotinylated probe DNA. Phage display system has already been well developed and used for isolation of antibodies and inhibitor peptides and for characterization of protein-protein and protein-peptide interactions. However, it has never used for DNA-protein interaction as far as we know, due to a lack of idea to use adequate DNA holding system (e.g. combination of SAPMP and biotinylated probe DNA) in phage display. This is the novel point of our usage. T7 phage has been used for this phage display, because (1) T7 phage has a fast replication cycle and a high cloning efficiency in Escherichia coli (E. coli) cells; (2) construction of phage library is easy; (3) lyses process of transfected $E$. coli is not necessary and (4) the target gene can be directly prepared from the isolated phage clone and used for both further cloning steps and molecular biological characterizations. We believed that our new T7 phage display combined with a biotin-streptavidin paramagnetic binding system is a very powerful system for an isolation of DNA binding proteins. Moreover, our system can be theoretically applied to very wide range of target DNA fragment (e.g., 50 bp to 1000 bp).

As a model experiment in this study, our protocol was applied to isolate regulatory proteins of AtGST11 gene [Arabidopsis thaliana (Arabidopsis) glutathione Stransferase gene] whose expression is induced by various abiotic stresses (Ezaki et al. 2004). Among the isolated ten candidates, the two clones could show a DNA binding activity by gel shift assay. This result proves that our technique can be widely applied for characterization of protein-DNA interaction, especially for isolation of transcription factors.

\section{MATERIALS AND METHODS}

\section{Conditions of plant and bacterial growth}

A modified Murashige and Skoog medium (MS medium) (1/6 MS) described by Ezaki et al. (2004) was used for plant growth. Arabidopsis (ecotype Landsberg) was grown on the 1/6 MS medium under fluorescent illumination (approximately $50 \mu \mathrm{Em}^{-2} \mathrm{~s}^{-1}, 16 \mathrm{hrs}$ of light and $8 \mathrm{hrs}$ of darkness) at $22^{\circ} \mathrm{C}$. All E. coli cells were grown at $37^{\circ} \mathrm{C}$ in LB medium, and M9 medium was used for transfection of T7 phage to E. coli in our screening (Sambrook et al. 1989).

\section{Isolation of mRNA and construction of cDNA using T7 phage}

Young seedlings of Arabidopsis (14 days old) were treated with $100 \mu \mathrm{M}$ of $\mathrm{AlCl}_{3}$ solution (adjusted to $\mathrm{pH} 4.2$ ) for 4 or $8 \mathrm{hrs}$ to induce the gene-expression of AtGST11 (Ezaki et al. 2004). Total RNA was extracted from these plant samples using Trizol reagent (Invitrogen Corp.). Isolation and purification of mRNA was performed by using 
Table 1. List of the isolated Arabidopsis candidates in this screening.

\begin{tabular}{|c|c|c|c|c|c|}
\hline $\begin{array}{c}\text { Clone } \\
\text { No. }\end{array}$ & $\begin{array}{c}\text { Protein function of isolated } \\
\text { clone }\end{array}$ & $\begin{array}{c}\text { Size of } \\
\text { insert (bp) }\end{array}$ & $\begin{array}{c}\text { GenBank } \\
\text { Accession }\end{array}$ & $\begin{array}{c}\text { Locus Tag in Arabidopsis } \\
\text { (Annotation) }\end{array}$ & Homology (\%) \\
\hline 4 & Unknown protein & 914 & BT004545 & At3G29240 & 96 \\
\hline 9 & $\begin{array}{c}\text { ATP binding cassette transporter } \\
\text { protein }\end{array}$ & 879 & BT000519 & At5g64840 & 99 \\
\hline 13 & RING zinc finger protein & 812 & AY128352 & At1g63900 & 94 \\
\hline 17 & $\begin{array}{c}\text { Pathogenesis-related protein 5 } \\
\text { (PR-5) }\end{array}$ & 794 & AY059114 & At1g75040 & 97 \\
\hline 19 & $\begin{array}{c}\text { 14-3-3 protein (GF14u) } \\
\text { Photosystem II 10kDa } \\
\text { polypeptide }\end{array}$ & 866 & AY065274 & At3g02520 & 96 \\
\hline 29 & 877 & AY096544 & At1g79040 & 97 \\
\hline 40 & 40 ribosomal protein (S17) & 799 & BT000851 & At5g04800 & 97 \\
\hline 43 & $\begin{array}{c}\text { Homeodomain leucine zipper } \\
\text { protein 6 (ATHB6) }\end{array}$ & 556 & AY122903 & At2g22430 & 99 \\
\hline 45 & Vaculoar ATPase protein & 644 & AY117236 & At4g02620 & 100 \\
\hline 49 & 40 S ribosomal protein (S27A) & 629 & NM130279 & At2g47115 & 99 \\
\hline
\end{tabular}

R (resistant); I (intermediate); S (susceptible).

PolyAtrack mRNA isolation system III (Promega). These purified mRNA molecules were mixed together and used for a construction of cDNA library.

T7Select 10-3 Orient Express cDNA cloning system, oligo (dT) (Novagen) was used for a construction of cDNA library and for a screening system. This display vector can display 5 to 15 copies of fused protein with 10B capsid protein on the surface of this phage particle. The recombinant phages were amplified by an infection to $E$. coli BL 5403 (Novagen) at $37^{\circ} \mathrm{C}$. The procedure for cloning cDNA in T7Select vector, purification of $\mathrm{T} 7$ phage from lysate and isolation of T7 phage DNA were followed to the T7Select System Manual (Novagen).

\section{Preparation of phage DNA and amplification of cDNA insert}

Extraction of T7 recombinant phage DNAs from phage particles was followed to Sambrook et al. (1989). Polymerase chain reaction (PCR) amplification of inserted cDNA in the recombinant T7 phage was performed using the two primers, T7 forward primer; ggagctgtcgtattccagt and T7 reverse primer; acccctcaagacccgttt.

\section{Purification of His-tag protein from E. coli transformants}

Full length cDNAs derived from Arabidopsis (BT004545, AY128352 and AY122903; Table 1), which showed high homology to our isolated clones, were obtained from RIKEN. Open reading frames of these cDNA were inserted into a high expression vector, pET SUMO (Invitrogen), and introduced into E. coli BL21(DE3). Over-expressing transformants were spin down and then disrupted by a sonication. Purification of SUMO fusion protein from the E. coli extract was performed using ProBond Purification System (Invitrogen). Purified proteins were furthermore digested with a protease at $25^{\circ} \mathrm{C}$ for 3 hrs to remove the SUMO peptide.

\section{Gel shift assay}

Gel shift assay was performed using digoxigenin (DIG) Gel Shift Kit (Roche) and following its protocol. The 3'-ends of the eight probe DNA fragments were previously labeled with DIG-11-ddUTP by a terminal deoxynucleotidyl transferase (Promega) at $37^{\circ} \mathrm{C}$ for $1 \mathrm{hr}$. The $3^{\prime}$-end labeled DNA probe $(0.1$ pmol $)$ was mixed with the purified proteins described above $(15 \mathrm{pmol})$ in $10 \mu \mathrm{l}$ scale at $25^{\circ} \mathrm{C}$ 
for 30 min. After $8 \%$ polyacrylamide electrophoresis, the separated DNA molecules were blotted to a nylon membrane and then detected by DIG detection kit (Roche).

\section{RESULTS AND DISCUSSION}

\section{Construction of a cDNA library derived from Al treated Arabidopsis}

To estimate whether our new approach actually can be applied for a screening of DNA binding proteins or not, we tried to isolate transcription factors which bind to the promoter region of the Al stress induced AtGST11 gene in Arabidopsis. As the AtGST11 gene shows the maximum induction by an exposure to $\mathrm{Al}$ stress for 4 to 8 hrs (Ezaki et al. 2004), we supposed that the transcription factors of this gene were probably expressed almost the same period. Therefore we isolated the mRNA from the plant samples exposed to Al stress for 4 or 8 hrs and used for a construction of a T7 phage recombinant cDNA library.

\section{Characterization of the isolated clones}

Approximately $8.0 \times 10^{4}$ recombinant phages in the constructed phage library were applied to the first round of this screening shown in Figure 1. After the repeated three rounds of the screening, the recovered phage solution was mixed with host $E$. coli cells (BL5403) and plated on the LB agar plates to generate single phage plaques. Fifty of single phage plaques were selected randomly to determine the length of inserts by PCR amplification, using the two T7 primers. Thirty five clones carried less than 250 bp fragments, but the remained 15 clones contained 300 bp $1.2 \mathrm{~kb}$ DNA fragments (data not shown). Ten clones carrying the cDNA fragments longer than 500 bp (clone 4, $9,13,17,19,29,40,43,45$ and 49 ) were sequenced and the DNA data was applied to Genbank database (http://www.ncbi.nlm.nih.gov/) and two Arabidopsis databases (http://www.arabidopsis.org/ and http://arabidopsis.med.ohio-state.edu/AtTFDB/). All sequences indicated high homology to Arabidopsis cDNAs (more than 94\%, Table 1).

Among these ten clones, two (\#13 and \#43) were the most likely transcription factors for AtGST11 gene. Clone \#13 showed a high homology to a RING zinc finger protein (Accession number, AY128352) and can be included within HCa-RING type family (Figure 2a). Many plant RING domain proteins have a role in ubiquitination pathway during cold stress (Lee et al. 2001), and are involved in self-incompatibility (O’Brien et al. 2004). The ubiquitin feature of the RING domain acts as one of three ubiquitin enzymes (E1, E2 and E3) (Crowe and Candido, 2004; O’Brien et al. 2004; Stone et al. 2005). Moreover, this motif has been deduced as either protein-protein interaction domain or protein-DNA interaction domain. The second candidate, \#43, showed a 99\% homology to Homeobox leucine zipper 6 protein (AtHB6) which belongs to a subfamily of homeodomain leucine zipper protein (HD-

\section{a. \#13 (AY128352)}

$\begin{array}{lllll}10 & 20 & 30 & 40 & 50\end{array}$

MIPWGGVTCC LSAAALYLG RSSGRDAEVL ETVTRVNOLK ELAQLLELDS

$\begin{array}{lllll}60 & 70 & 80 & 90 & 100\end{array}$

KILPFIVAVS GRVGSETPIK CEHSGIRGVI VEETAEOHFL KHNETGSWVO

$\begin{array}{lllll}110 & 120 & 130 & 140 & 150\end{array}$

DSALMLSMSK EVPWFLDDGT SRVHVMGARG ATGFALTVGS EVFEESGRSL

$\begin{array}{lllll}160 & 170 & 180 & 190 & 200\end{array}$

VRGTLDYLQG LRMLGVKRIE RVLPTGIPLT IVGEAVKDDI GEFRIQKPDR

$\begin{array}{lllll}210 & 220 & 230 & 240 & 250\end{array}$

GPFYVSSRSL DQLISNLGKW SRLYKYASMG FTVLGVELIT KHVIDSVLER

$\begin{array}{lllll}260 & 270 & 280 & 290 & 300\end{array}$

RRRRQLOKRV LDARAKRAEL ESEGSNGTRE SISDSTKKED AVPDLCVICI

$\begin{array}{llll}310 & 320 & 330 & 340\end{array}$

EQEYNAVFVE CGHMCCCTAC SSHETSCPLC RRRIDLAVKT YRH

b. \#43 (AY122903)

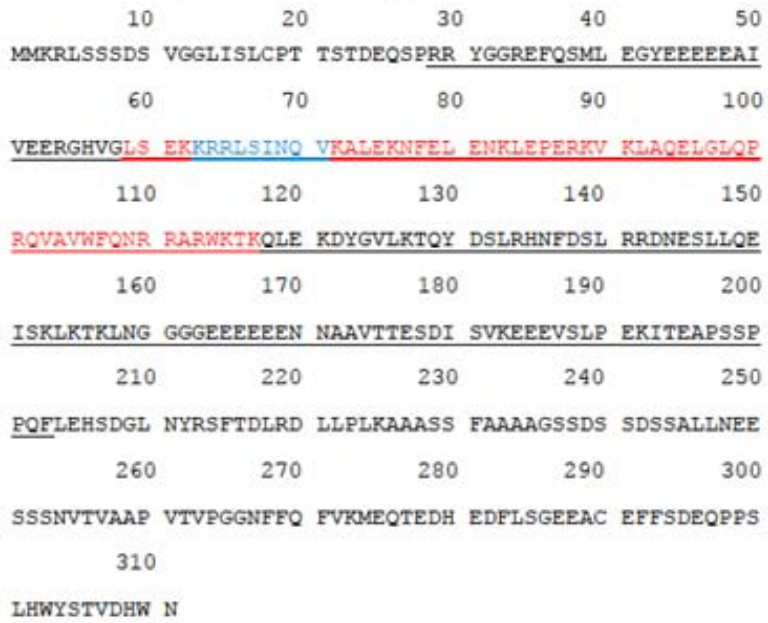

Figure 2. Amino acid sequence of \#13 (AY128352) (a) and \#43 (AY122903) (b). Underlined part was found in each isolated phage clone as DNA sequence. Red sequences in AY128352 and AY122903 were an HCa-RING domain and a HD domain, respectively. The consensus motif (KRRLSINQV) within the HD domain, which has been deduced to relate to phosphorylation and DNA binding of AtHB6, was shown as blue sequence in (b).

Zip) family (Figure 2b). Arabidopsis contains more than 25 HD-Zip proteins and they have been grouped into 4 classes (Johanesson et al. 2001; Ohashi-Ito et al. 2005). AtHB6 is a Class I type HD-Zip protein and involved in the abscisic acid related response which is regulated mainly by desiccation, osmo-regulation and programmed cell death (Soderman et al. 1999; Mayda et al. 1999; Himmelbach et al. 2002; Henriksson et al. 2005). The consensus motif (KRRLSINQV) was found within the HD domain of AtHB6. This motif has been deduced to relate to phosphorylation and DNA binding activity of AtHB6 (Blom et al. 1999). 

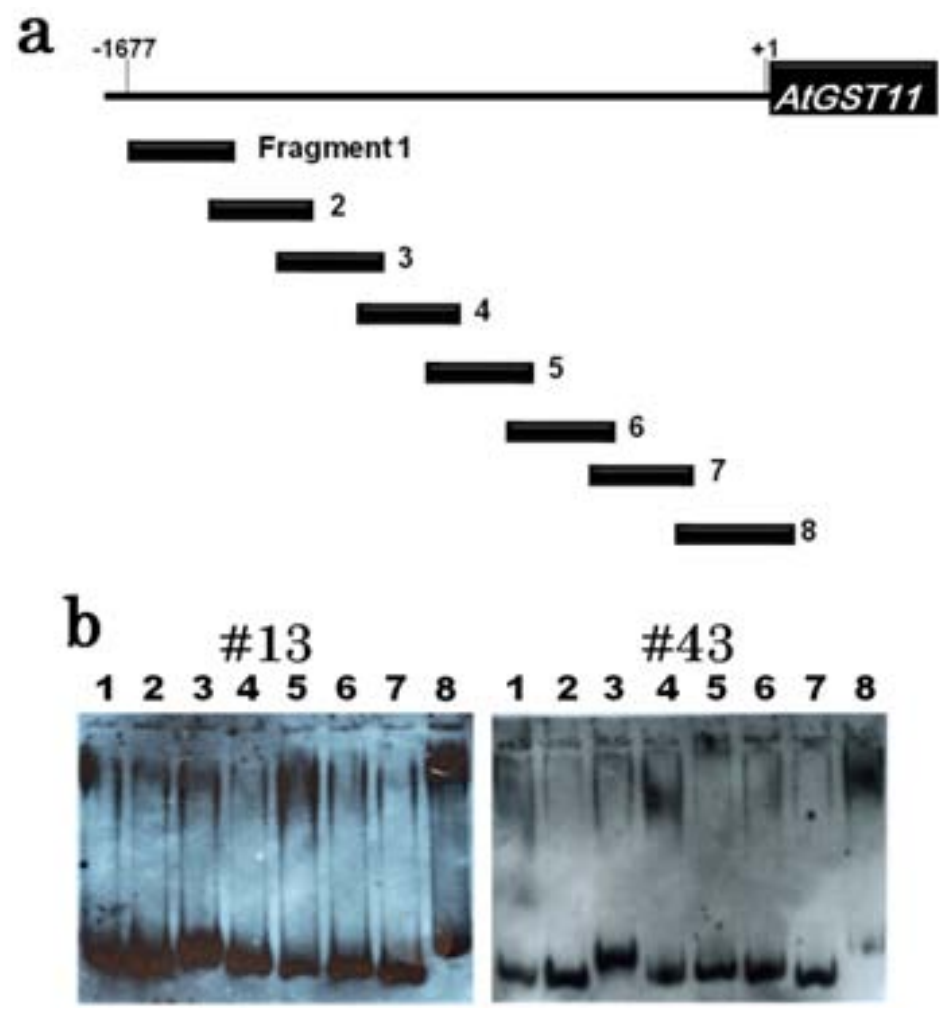

Figure 3. Results of gel-shift assay for the AtGST11 promoter region. (a) Series of DNA probes used for this gel-shift assay. Approximately the $1677 \mathrm{bp}$ upstream region and the $80 \mathrm{bp}$ of open reading frame of the AtGST11 gene was divided into the eight overlapped DNA segments (Fragment 1; -1677 -1394 bp Fragment 2, -1467 -1193 bp; Fragment 3, -1288 -1004 bp; Fragment 4, 1079 -806 bp; Fragment 5, -895 -611 bp; Fragment 6, -683 -397 bp; Fragment 7, -463 -189 bp; Fragment 8, -234 +80 bp) and then labeled with Dig-11-dd-UTP at the 3' terminal end. These Dig-labeled DNA probes were mixed with isolated \#13 or \#43 proteins and then applied to polyacrylamide gel electrophoresis. (b) Result of gel-shift assay for \#13 (Left) and \#43 (Right). Lane numbers showed the DNA fragment number used for the binding reaction.

\section{Result of gel shift assay}

To confirm the DNA binding activity of these two clones, gel shift assay was performed using the purified proteins. Eight overlapped DNA fragments covering approximately $1750 \mathrm{bp}$ of the 5'-upstream region of the AtGST11 gene were independently used as DNA probes (Figure 3a). In case of \#13 protein, a clear DNA shift and a weak DNA shift were detected in the reactions using probe 8 and 5 , respectively (Figure $3 \mathrm{~b}$ ). The \#43 protein showed a strong and a weak binding activity to the probe 8 and 4 , respectively (Figure 3b). All of these DNA shifts were disappeared by an addition of extra amount of non-labeled same probe DNA as competitor (data not shown). These results indicated that both of the two transcription factors, RING finger protein and ATHB6 protein, can bind to the upstream region of the AtGST11 gene in Arabidopsis.

\section{Other isolated clones}

The DNA sequences of other eight isolated candidates were not homologous to those of any transcription factors and all of them except for \#4 have their own functions in different metabolisms (Table $1, \# 4$ is an unknown protein). Simple explanation may be that these proteins were captured as noise in our screening. Another possibility is that some of these proteins can make protein-protein interactions with other proteins encoded by other phage clones in our screening. It was speculated that they cooperatively bind to the promoter region of the AtGST11 as hetero-proteincomplex. Moreover, we cannot exclude a possibility that some of these proteins have a DNA binding activity as their novel function. These hypotheses need further experimental supports to be approved. To decrease the noise in this screening, an increase of cycle number of the screening may be effective. DNA homology search of the isolated clones after the DNA sequencing is also very helpful to select the candidates for the gel shift assay. Clone \#4 was an Arabidopsis clone BT004545 (Table 1), but its function in metabolisms was unknown. As there was no shifted bind in our gel shift assay, we concluded that this clone is probably not a transcription factor (data not shown).

The captured phages in this screening system are candidate clones that have a DNA binding activity. And it is expected that the clones encode transcription factors which can regulate expression of a target gene. We strongly believe that this technique can be applied to a comprehensive 
screening of transcription factors for the wide range of promoter region of the target gene within a short period without any complicated handlings like yeast one hybrid system.

\section{REFERENCES}

BLOM, Nikolaj; GAMMELTOFT, Steen and BRUNAK, Soren. Sequence and structure-based prediction of eukaryotic protein phosphorylation sites. Journal of Molecular Biology, December 1999, vol. 294, no. 5, p. 1351-1362.

CROWE, Emily and CANDIDO, E. Peter M. Characterization of $C$. elegans RING finger protein 1 , a binding partner of ubiquitin-conjugating enzyme 1 . Developmental Biology, January 2004, vol. 265, no. 2, p. 446-459.

EZAKI, Bunichi; SUZUKI, Masakatsu; MOTODA, Hirotoshi; KAWAMURA, Masako; NAKASHIMA, Susumu and MATSUMOTO, Hideaki. Mechanism of gene expression of Arabidopsis Glutathione S-transferase, AtGST1, and AtGST11 in response to Aluminum stress. Plant Physiology, April 2004, vol. 134, no. 4, p. 16721682.

HENRIKSSON, Eva; OLSSON, Anna S.B.; JOHANNESSON, Henrik; HANSON, Johannes; ENGSTROM, Peter and SODERMAN, Eva. Homeodomain leucine zipper class I genes in Arabidopsis. Expression patterns and phylogenetic relationships. Plant Physiology, September 2005, vol. 139, no. 1, p. 509-518.

HIMMELBACH, Axel; HOFFMANN, Thomas; LEUBE, Martin; HOHENER, Beat and GRILL, Erwin. Homeodomain protein AtHB6 is a target of the protein phospatase ABI1 and regulates hormone responses in Arabidopsis. The EMBO Journal, June 2002, vol. 21, no. 12, p. 3029-3038.

JOHANESSON, Henrik; WANG, Yan and ENGSTROM, Peter. DNA-binding and dimerisation preferences of Arabidopsis homeodomain-leucine zipper transcription factors in vitro. Plant Molecular Biology, January 2001, vol. 45, no. 1, p. 63-73.

LEE, Hojoung; XIONG, Liming; GONG, Zhizhong; ISHITANI, Manabu; STEVENSON, Becky and ZHU, JianKang. The Arabidopsis HOS1 gene negatively regulates cold signal transduction and encodes a RING finger protein that displays cold-regulated nucleo-cytoplasmic partitioning. Genes and Development, April 2001, vol. 15, no. 7, p. 912-924.

MAYDA, Esther; TORNERO, Pablo; CONEJERO, Vicente and VERA, Pablo. A tomato homeobox gene (HDZip) is involved in limiting the spread of programmed cell death. Plant Journal, December 1999, vol. 20, no. 5, p. 591-600.
O'BRIEN, Martin; MAJOR, Geneviève; CHANTHA, SierChing and MATTON, Daniel P. Isolation of S-RNase binding proteins from Solanum chacoense: identification of an SBP1 (RING finger protein) orthologue. Sexual Plant Reproduction, July 2004, vol. 17, no. 2, p. 81-87.

OHASHI-ITO, Kyoko; KUBO, Minoru; DEMURA, Taku and FUKUDA, H. Class III homeodomain leucine-zipper proteins regulate xylem cell differentiation. Plant and Cell Physiology, October 2005, vol. 46, no. 10, p. 1646-1656.

SAMBROOK, J.; FRITSCH, E.F. and MANIATIS, T. Molecular Cloning. A laboratory manual. $2^{\text {nd }}$ Ed. New York; Cold Spring Harbor Laboratory Press, 1989. 1659 p. ISBN 0-87969-309-6.

SODERMAN, Eva; HJELLSTROM, Mattias; FAHLESON, Jan and ENGSTROM, Peter. The HD-Zip gene AtHB6 in Arabidopsis is expressed in developing leaves, roots and carpels and up-regulated by water deficit conditions. Plant Molecular Biology, April 1999, vol. 40, no. 6, p. 1073-1083.

STONE, Sophia L.; HAUKSDOTTIR, Herborg; TROY, Andrew; HERSCHLEB, Jill; KRAFT, Edward and CALLIS, Judy. Functional analysis of the RING-type ubiquitin ligase family of Arabidopsis. Plant Physiology, January 2005, vol. 137, no. 1, p. 13-30. 